\title{
Mapeamento e potencialidades das trilhas da Universidade Federal de Lavras para educação ambiental e práticas recreativas na natureza
}

\author{
Mapping and potential of the trails of the Federal University of Lavras for environmental \\ education and recreational practices in nature \\ Mapeo y potencialidad de los senderos de la Universidad Federal de Lavras para educación \\ ambiental y prácticas recreativas en la naturaleza
}

Recebido: 25/01/2021 | Revisado: 26/01/2021 | Aceito: 28/01/2021 | Publicado: 07/02/2021

\author{
Rodrigo da Silva Naves \\ ORCID: https://orcid.org/0000-0003-0742-0166 \\ Escola Estadual Dona Sindá, Brasil \\ E-mail: rodrigo.naves@educacao.mg.gov.br \\ Rosângela Alves Tristão Borém \\ ORCID: https://orcid.org/0000-0002-5756-446X \\ Universidade Federal de Lavras, Brasil \\ E-mail: tristao@ufla.br \\ Emanuelle Aparecida da Costa \\ ORCID: https://orcid.org/0000-0001-9131-2218 \\ Universidade Federal de Lavras, Brasil \\ E-mail: manuhcosta_1@hotmail.com \\ Gustavo de Sousa Oliveira \\ ORCID: https://orcid.org/0000-0002-0291-2471 \\ Universidade Federal de Lavras, Brasil \\ E-mail: gustavodesousaoliveira867@gmail.com \\ Gleice Aparecida de Assis \\ ORCID: https://orcid.org/0000-0003-0239-1474 \\ Universidade Federal de Uberlândia, Brasil \\ E-mail: gleice@ufu.br \\ Franscinely Aparecida de Assis \\ ORCID: https://orcid.org/0000-0002-9996-3805 \\ Centro Universitário de Goiatuba, Brasil \\ E-mail: franscinelyagronomia@yahoo.com.br \\ Érica Alves Marques \\ ORCID: https://orcid.org/0000-0003-1382-5012 \\ Universidade Federal de Lavras, Brasil \\ E-mail: ericagroeng@yahoo.com.br
}

\begin{abstract}
Resumo
A Educação Ambiental tem se tornado uma grande aliada para a conscientização de boas práticas de saúde e convivência com meio ambiente. Objetivou-se com a realização desse trabalho mapear e classificar as trilhas existentes na Universidade Federal de Lavras, expondo o potencial das mesmas à sociedade por meio de palestras nas escolas estaduais e municipais da cidade. As trilhas foram mapeadas por caminhamento usando um aparelho GPS Garmin, modelo GPSMAP 62 sc. Posteriormente os dados coletados foram transferidos para o programa Base Camp, que tem como função traçar a rota do percurso, e em seguida os dados foram plotados para o Google Earth, fornecendo a imagem por satélite de toda a extensão da trilha. Com base no mapeamento das trilhas da Universidade Federal de Lavras, distinguem-se áreas com diferentes graus de declividade e ambientes florísticos e com fauna diversificada, o que instiga a sugestão de trilhas para alunos (as) em função da faixa etária. Para discentes do Ensino Fundamental I e II recomenda-se a Trilha das Lagoas, por apresentar baixo grau de declividade, fácil acesso, distância intermediária e pontos recreativos à beira das lagoas para práticas de piquenique. Já para alunos (as) do Ensino Médio, a Trilha da Capela e Trilha dos Eucaliptos, por apresentarem um ambiente mais diversificado, seria a mais indicada, sendo inclusive propícia para prática de atividades de aventura na natureza. O levantamento e classificação dessas áreas podem contribuir para futuras pesquisas em outros projetos dentro da Universidade.
\end{abstract}

Palavras-chave: Classificação das trilhas; Sensibilização ambiental; Práticas de lazer.

\begin{abstract}
Environmental Education has become a great ally for raising awareness of good health practices and living with the environment. The objective of this work was to map and classify the trails existing at the Federal University of
\end{abstract}


Lavras, exposing their potential to society through lectures at state and municipal schools in the city. The trails were mapped by walking using a Garmin GPS device, model GPSMAP 62 sc. Subsequently, the collected data were transferred to the Base Camp program, which has the function of tracing the route of the route, and then the data was plotted to Google Earth, providing the satellite image of the entire length of the trail. Based on the mapping of trails at the Federal University of Lavras, areas with different degrees of declivity and floristic environments are distinguished and with diverse fauna, which instigates the suggestion of trails for students according to the age group. For elementary school students I and II, the Lagoas Trail is recommended, as it has a low degree of slope, easy access, intermediate distance and recreational spots by the lagoons for fishing practices. As for high school students, the Capela Trail and the Eucalyptus Trail, as they have a more diversified environment, would be the most designated, being even conducive to the practice of adventure activities in nature. The survey and classification of these areas can contribute to future research in other projects within the University.

Keywords: Classification of trails; Environmental awareness; Practices of recreation.

\section{Resumen}

La Educación Ambiental se ha convertido en un gran aliado para concienciar sobre las buenas prácticas de salud y convivencia con el medio ambiente. El objetivo de este trabajo fue mapear y clasificar los senderos existentes en la Universidad Federal de Lavras, exponiendo su potencial a la sociedad a través de conferencias en escuelas estatales y municipales de la ciudad. Los senderos se mapearon caminando utilizando un dispositivo GPS Garmin, modelo GPSMAP 62 sc. Posteriormente, los datos recolectados fueron transferidos al programa Campo Base, que tiene la función de trazar la ruta de la ruta, y luego los datos fueron graficados a Google Earth, brindando la imagen satelital de toda la longitud del sendero. Con base en el mapeo de senderos de la Universidad Federal de Lavras, se distinguen áreas con diferentes grados de declive y ambientes florísticos y con fauna diversa, lo que instiga la sugerencia de senderos para los estudiantes según el grupo de edad. Para los alumnos de primaria I y II, se recomienda el sendero Lagoas, ya que tiene un grado bajo de pendiente, fácil acceso, distancia intermedia y lugares recreativos junto a las lagunas para prácticas de pesca. En cuanto a los estudiantes de secundaria, el Capela Trail y el Eucalyptus Trail, por tener un entorno más diversificado, serían los más designados, siendo incluso propicios para la práctica de actividades de aventura en la naturaleza. El relevamiento y clasificación de estas áreas puede contribuir a futuras investigaciones en otros proyectos dentro de la Universidad.

Palabras clave: Clasificación de senderos; Conciencia ambiental; Prácticas de recreación.

\section{Introdução}

Cada vez mais o mundo tem se mostrado interessado nas questões relacionadas à conservação do meio ambiente. O desenvolvimento de ideias que relacionem lazer, saúde e educação têm contribuído para a melhoria da qualidade de vida e conscientização ambiental. Na Universidade Federal de Lavras, projetos que envolvam a promoção de práticas ambientais corretas têm colaborado para realização de trabalhos nas áreas de cultura e extensão. Estas ações têm levado para a comunidade de Lavras e região, trabalhos que contribuem para uma maior interação entre a comunidade acadêmica e a população.

As trilhas sempre foram utilizadas pela humanidade para suprir a necessidade de deslocamento. Porém, nas últimas décadas, ocorreram mudanças em relação aos valores atribuídos às trilhas, pois a procura por ambientes que proporcionem um contato com a natureza tem aumentado significativamente nos tempos atuais (Andrade, 2003). Segundo Menghini (2005) pode-se encontrar vários tipos de trilhas, com aspectos e características diferentes, dentre elas têm-se as trilhas religiosas, trilhas de aventura, trilhas de caça, trilhas interpretativas, trilhas educativas, trilhas para transporte/ou comunicação. Todas são resultados da interferência humana na natureza, produzidas pelas mais diversas necessidades do homem, como bem-estar, conhecimento, subsistência, adrenalina ou consciência ambiental. A prática de atividades físicas na natureza, lazer e educação ambiental tem acompanhado essa tendência. Para melhor aproveitamento desses espaços, trilhas preservadas, bem construídas e devidamente mantidas, protegem o meio ambiente e oferecem ao público maior segurança, conforto e bem estar (Andrade \& Rocha, 2008).

Visando colaborar com políticas ambientais e educacionais corretas, a Educação Ambiental utiliza como processo pedagógico, a tematização de conteúdos como cidadania, sustentabilidade e meio ambiente para conscientização e apropriação de valores que permitem ao indivíduo pensar e refletir sobre os problemas ambientais que afligem a humanidade. De acordo 
com Silva et al. (2012), as trilhas ecológicas são um recurso utilizado pela Educação Ambiental como prática metodológica para o ensino e conscientização por meio de prática ambientais em meio a natureza. A Educação Ambiental busca educar por meio de ideias que tem em seu bojo o intuito de problematizar, discutir e (re) pensar os danos causados ao meio ambiente. A melhor maneira de realizar este objetivo seria por meio de valores, respeito e educação (Ambrósio, Borém \& Santos, 2011). As trilhas ecológicas por sua vez têm auxiliado na Educação Ambiental, visto que por ser uma prática em meio ao ar livre, proporciona aos seus praticantes momentos de contato direto com a natureza, colaborando para despertar sensações, atitudes e valores, assim como promover a educação socioambiental.

Segundo Pelicioni (1998), a Educação Ambiental tem como objetivo mudar o modo de vida das pessoas, promovendo a formação da conscientização e de atitudes mais responsáveis. A Educação Ambiental deve se transformar em ação por meio de práticas político-pedagógicas e desta maneira intervir para construção da cidadania e melhoria da qualidade de vida da população. De acordo com os Parâmetros Curriculares Nacionais (PCNs) (Brasil, 1997), é fundamental que a Educação Ambiental seja discutida e abordada claramente no meio educacional. Por ser um tema transversal e de caráter sociocultural, este tem a possibilidade de ser um conteúdo ministrado em qualquer disciplina. Segundo Domingues, Kunz \& Araújo (2011), a interdisciplinaridade proporciona ao professor de Educação Física a oportunidade de trabalhar a Educação Ambiental junto a outras áreas do conhecimento.

Desta forma, objetivou-se com a realização desse trabalho mapear e classificar as trilhas existentes na Universidade Federal de Lavras, expondo o potencial das mesmas à sociedade por meio de palestras nas escolas estaduais e municipais da cidade.

\section{Metodologia}

Este trabalho foi desenvolvido no Campus da Universidade Federal de Lavras (UFLA), localizada na cidade de Lavras, estado de Minas Gerais, entre as coordenadas $21^{\circ} 14^{\prime} 30^{\prime \prime}$ de latitude sul e $44^{\circ} 00^{\prime} 10^{\prime \prime}$ de longitude oeste.

\subsection{Caracterização da UFLA}

O processo de urbanização acarreta impactos sobre o meio ambiente, afetando de forma negativa o solo, os rios, nascentes, a fauna e flora. Na UFLA não foi diferente. Com o crescimento da universidade, novas áreas tiveram que ser exploradas para expansão. Porém, motivados pelo ideal de sustentabilidade, equilíbrio e conscientização, o desenvolvimento arquitetônico elaborado pela instituição respeita ao máximo a aplicação desses conceitos tão importantes para a sociedade, tentando causar menor dano possível às áreas e à biodiversidade.

A Universidade Federal de Lavras possui uma excelente estrutura física, ocupando a $8^{\mathrm{a}}$ posição entre as melhores universidades do Brasil e a $2^{\mathrm{a}}$ posição em Minas Gerais (Caetano, 2017). Segundo pesquisa divulgada pela GreenMetric 2017, a UFLA aparece no ranking como uma das instituições mais sustentáveis do Brasil, ocupando a $35^{\mathrm{a}}$ em todo o mundo (Lima, 2016). A grande preocupação com o meio ambiente e recomposição florística das áreas impactadas pelo crescimento acelerado da universidade, fez da UFLA um exemplo de instituição que valoriza a natureza, com políticas internas que priorizam o desenvolvimento sustentável.

Na UFLA a preocupação com o meio ambiente está retratada no Plano Diretor da Universidade. Neste projeto destaca-se construções como a avenida central, o centro de convivência e o estímulo ao convívio em meio à natureza. A criação da brigada de incêndio para controlar possíveis perigos de incêndios nas áreas verdes da universidade, a captação da água da chuva para abastecimento das lagoas, e o gerenciamento dos resíduos sólidos produzidos, são algumas das iniciativas implementadas dentro da Universidade (Dias, 2008, citado por Silva, 2009). Atualmente, os resíduos sólidos produzidos na UFLA são enviados à Estação de Tratamento de Esgoto (ETE), e os restos de alimentos produzidos pelo Restaurante 
Universitário (RU) são encaminhados para compostagem em local adequado.

Estes são apenas alguns exemplos, visto que muitos projetos de pesquisa e extensão são realizados no intuito de colaborarem para o desenvolvimento de atitudes responsáveis com meio ambiente. Na Figura 1 é possível observar a UFLA e toda sua extensão, como a parte arquitetônica, as áreas verdes e algumas trilhas dentro do campus.

Figura 1. Ilustração do campus da UFLA.

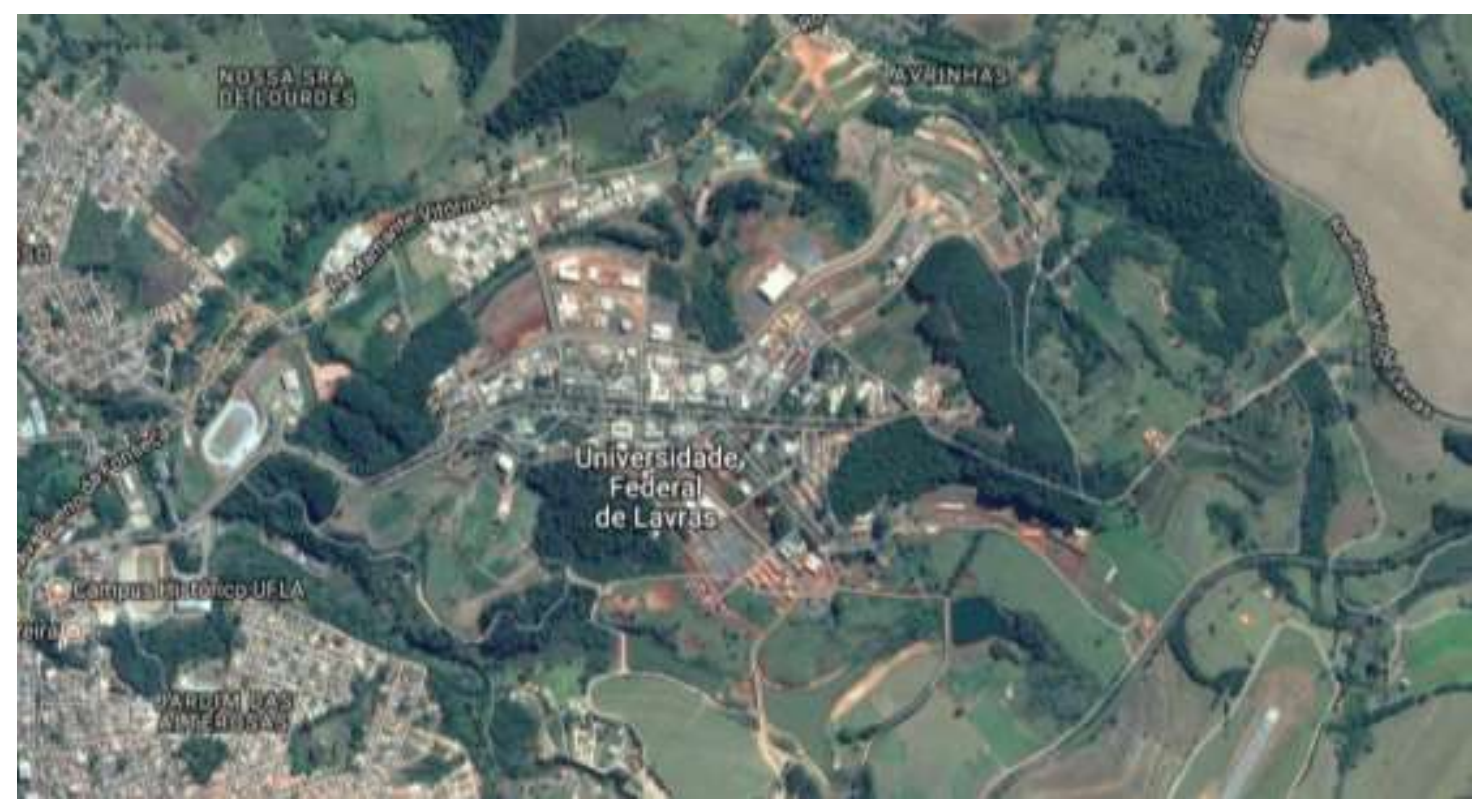

Fonte: Autores.

\subsection{Caracterização das trilhas da UFLA}

As trilhas da UFLA são utilizadas para fins administrativos de segurança, prevenção contra incêndios, além de serem utilizadas por visitantes que buscam lazer e prática de atividades físicas, como caminhada (Figura 2). A universidade possui uma área total de 584 ha, sendo que 49,22 ha representam áreas preservadas (Silva, 2009).

De acordo com Oliveira et al. (2010), nesse local existem estradas vicinais, caminhos e trilhas. Ao longo da trilha podem-se encontrar lagoas, nascentes, áreas de plantio, áreas de reflorestamento, fragmentos de florestas naturais, além de aves, mamíferos e invertebrados. O índice de diversidade de espécies de aves é grande, apesar do restrito tamanho dessas áreas (D’ Ângelo Neto et al., 2009). 
Figura 2. Trilha das Lagoas.

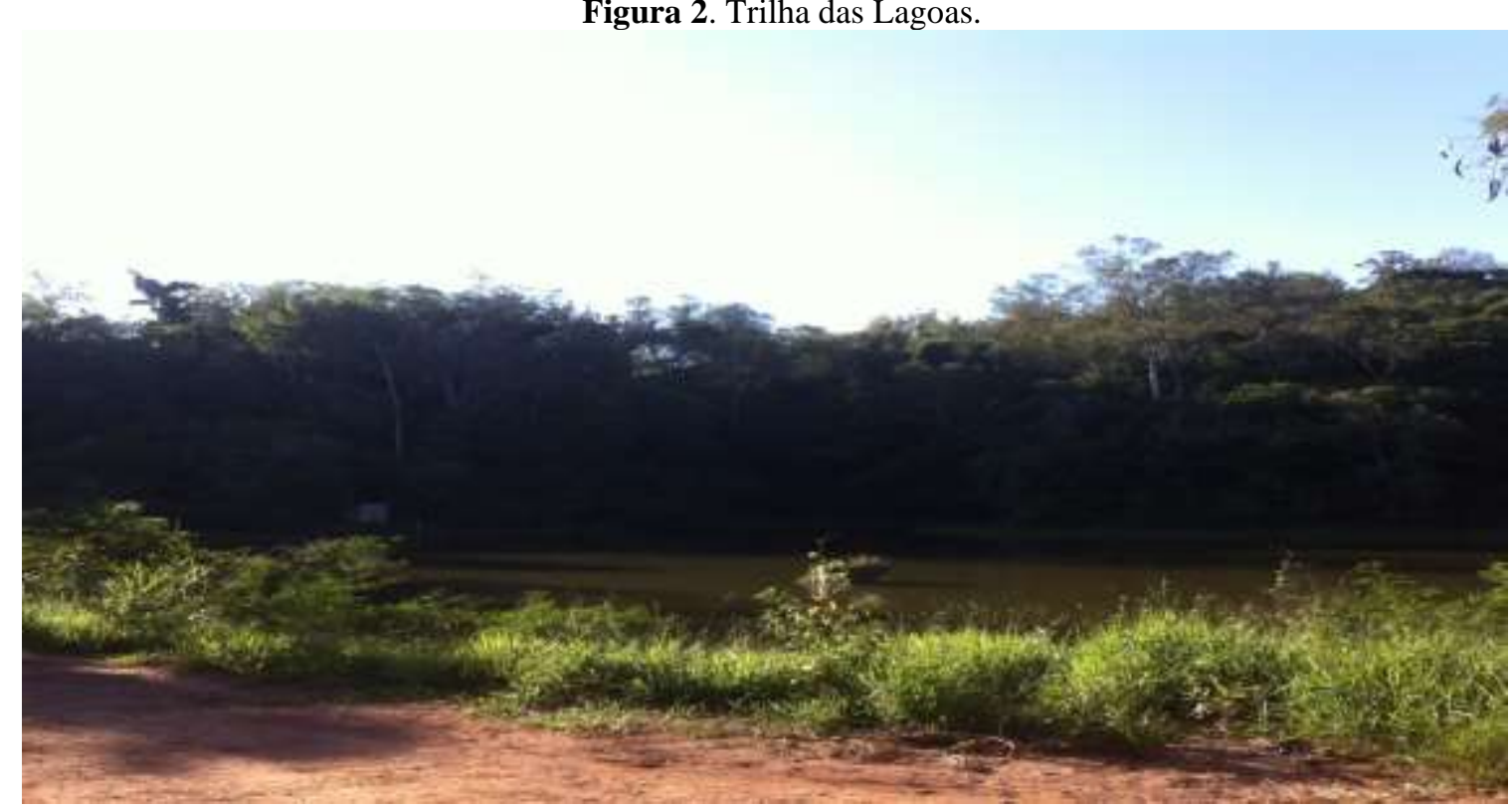

Fonte: Autores.

\subsection{Mapeamento das trilhas}

A metodologia empregada na pesquisa foi a quali-quantitativa (Pereira et al., 2018). As trilhas foram mapeadas por caminhamento usando um aparelho GPS Garmin, modelo GPSMAP 62 sc. Posteriormente os dados coletados foram transferidos para o programa Base Camp, que tem como função traçar a rota do percurso, e em seguida os dados foram plotados para o Google Earth, fornecendo a imagem por satélite de toda a extensão da trilha (Figura 3).

Figura 3. Trilhas mapeadas na UFLA.

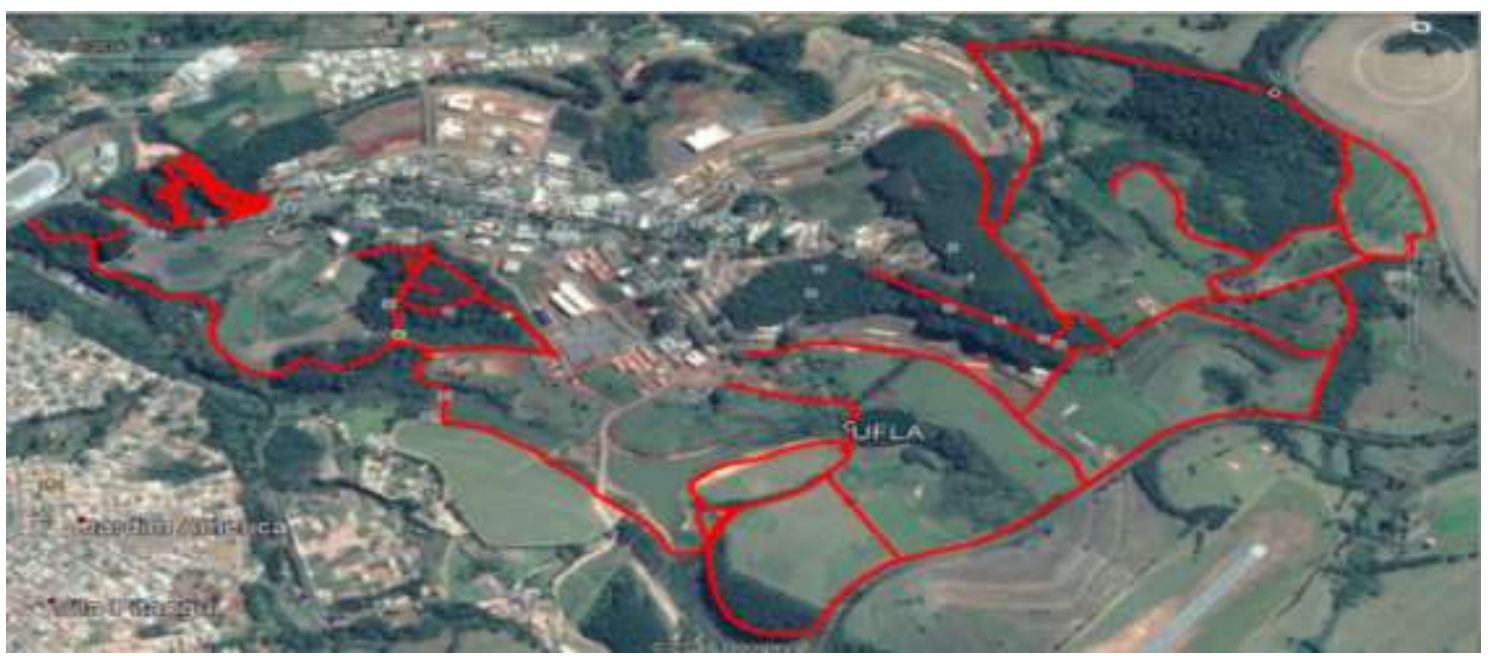

Fonte: Autores.

\subsection{Escolas visitadas}

Foram ministradas palestras com conteúdos vinculados à Educação Ambiental referente ao Projeto Trilhas da UFLA em quatro escolas do município: Escola Municipal Paulo Meniccuci, Escola Municipal Padre Dehon, Escola Estadual Firmino Costa e Escola Estadual Dr. João Batista Hermeto. 


\subsection{Palestras e vídeo}

Durante a palestra foram abordados temas como água, flora e fauna, com o objetivo de levar ao conhecimento do público a existência das trilhas na UFLA por meio de vídeo e fotos das trilhas. Para criação desse vídeo foi utilizado o programa Filmora Video Editor. O vídeo tem duração de 3min e 24s segundos, filmado com uma câmera especialmente feita para passeios ciclísticos.

Nas apresentações foram utilizados notebook, data show, caixa de som e o espaço fornecido pela escola. As palestras foram agendadas com antecedência, sempre com a supervisão dos docentes.

\section{Resultados e Discussão}

\subsection{Levantamento e mapeamento das trilhas}

As trilhas presentes na UFLA percorrem quase todo o campus da universidade, tendo seu início próximo à nova pista de atletismo. A Figura 4 mostra todas as trilhas mapeadas na Universidade. São trilhas com um percurso relativamente grande, por isso foi realizada a divisão dessas áreas de acordo com as denominações que são referidas popularmente, já que não existem registros oficiais dos nomes dessas trilhas.

Figura 4. Trilhas mapeadas com GPS.

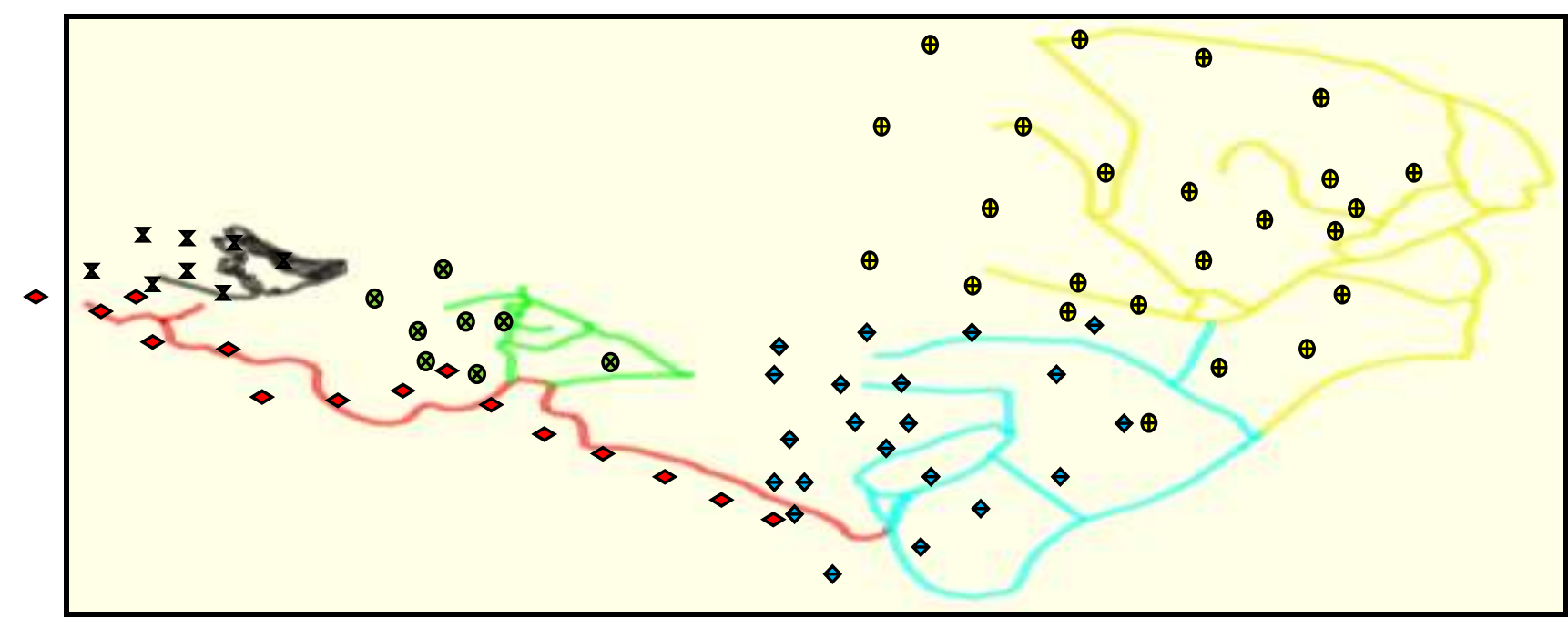

Trilha das Lagoas.

QTrilha da Capela.

Trilha da Zootecnia.

\# Trilha da Estação Experimental da EPAMIG (Citado por D`Angelo Neto et al, 2009).

Trilha dos Eucaliptos (Próximo à Ecologia).

Fonte: Autores.

Abaixo estão alguns dados de distância, elevação e grau de declividade das trilhas mapeadas na UFLA (Tabela 1): 
Tabela 1. Distância, elevação e grau de declividade das trilhas mapeadas.

\begin{tabular}{lccc}
\hline \multicolumn{1}{c}{ Trilhas } & Distância & & Elevação \\
\hline Trilha das Lagoas & $2.511 \mathrm{~m}$ & Mínima: $850 \mathrm{~m}$ & Máxima: $926 \mathrm{~m}$ \\
Trilha da Capela & $1.744 \mathrm{~m}$ & Mínima: $874 \mathrm{~m}$ & Máxima: $918 \mathrm{~m}$ \\
$\begin{array}{l}\text { Trilha da Zootecnia } \\
\text { Trilha da Est. Exp. EPAMIG }\end{array}$ & $5.149 \mathrm{~m}$ & Mínima: $880 \mathrm{~m}$ & Máxima: $956 \mathrm{~m}$ \\
$\begin{array}{l}\text { Trilha Dos Eucaliptos (Próximo à } \\
\text { Ecologia) }\end{array}$ & $7.790 \mathrm{~m}$ & Mínima: $938 \mathrm{~m}$ & Máxima: $993 \mathrm{~m}$ \\
\end{tabular}

Fonte: Autores.

Ao analisar as trilhas, pode-se observar que são realmente extensas, sendo a trilha da Estação Experimental da EPAMIG a mais longa, com 7.790 metros. A extensão total das trilhas é de 19.694 m, ou seja, quase 20 km de trilhas dentro da UFLA, todas de fácil acesso e bem estruturadas. Em relação ao nível de elevação pode-se observar que a mínima é de 850 m e a máxima de $993 \mathrm{~m}$ de altitude, $74 \mathrm{~m}$ acima da cidade de Lavras que possui uma altitude total de $919 \mathrm{~m}$. Quanto ao grau elevação, destaca-se a Trilha da Zootecnia (11,8\%), o que sugere terrenos com maior ondulação. Esses dados são importantes para a classificação das trilhas quanto ao grau de dificuldade e intensidade.

\subsection{Classificação das trilhas: forma}

As trilhas podem ser classificadas seguindo orientações específicas e objetivas. Para este estudo, foi realizada uma análise para cada área dessas trilhas (Figura 5), visto que cada uma possui aspectos que podem ser diferenciados segundo essas categorizações. As trilhas mais comuns na UFLA são:

a) Trilhas Circulares: oferecem para quem caminha por essa trilha a oportunidade de voltar ao ponto de partida sem repetir o percurso ou cruzar com outros visitantes.

b) Trilha Atalho: são trilhas que apresentam inicio e fim em diferentes pontos da trilha ou caminhos principais. 
Figura 5. Classificação das trilhas em relação às formas: A) Trilha das Lagoas. - B) Trilha da Capela. - C) Trilha da Zootecnia. - D) Trilha da Estação da Experimental da EPAMIG.

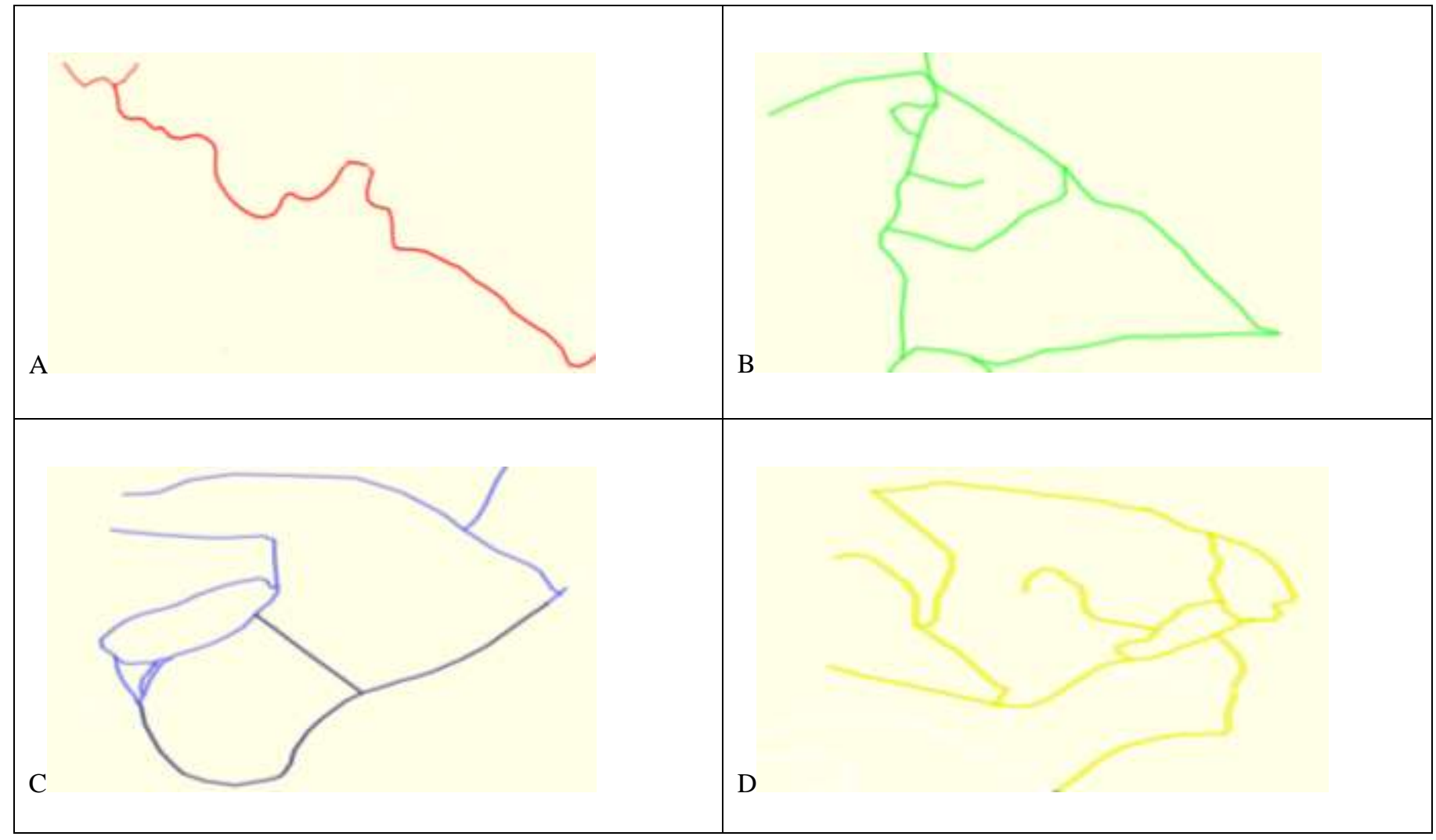

Fonte: Autores.

Verificam-se na Trilha das Lagoas (Figura 5A) características mais semelhantes à trilha atalho. Já as trilhas B, C e D apresentam características similares às trilhas circulares e atalho.

A trilha apresentada na Figura 6 não faz conexão com as outras, em função de ser uma trilha feita para treino e competições de mountain bike. Essa trilha possui caminhos muito estreitos, quase se cruzando ao longo do percurso. A forma que mais se encaixa nessa trilha é a de atalho porque apresenta início e fim em diferentes pontos. 
Figura 6. Trilha dos Eucaliptos.

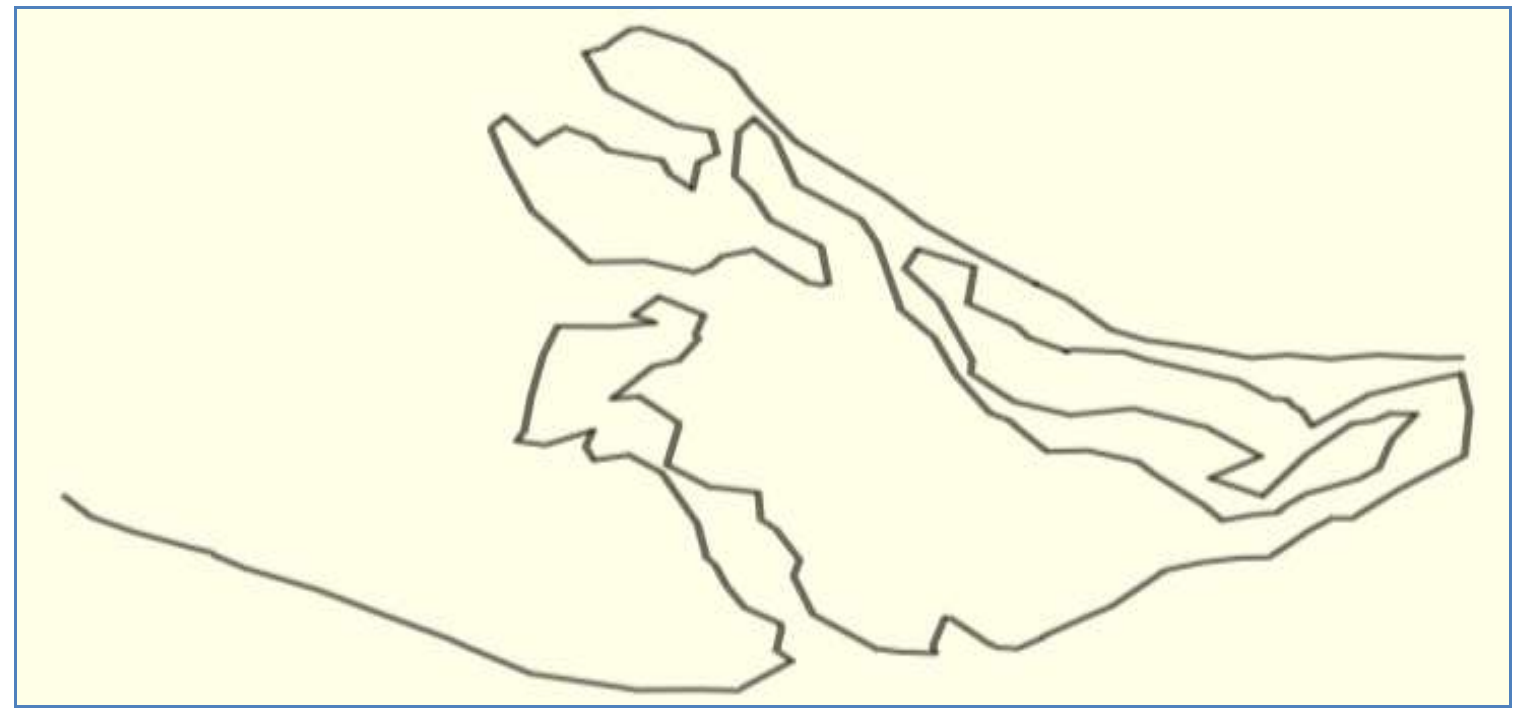

Fonte: Autores.

\subsection{Grau de dificuldade e intensidade}

A classificação do grau de dificuldade e intensidade das trilhas é determinada de duas formas: a primeira por meio de perguntas aos caminhantes após o término da trilha, e a segunda classificação pode ser realizada mensurando alguns aspectos que caracterizam a trilha, como tamanho da trilha, presença de obstáculos, necessidade de condicionamento físico, técnicas específicas, experiência básica, necessidade de mochilas ou pernoite na trilha (Andrade \& Rocha, 2008).

Nas trilhas da UFLA foram encontradas apenas algumas dessas características como tamanho da trilha, presença de obstáculos e necessidade de condicionamento físico. Para conclusão deste tópico, foi adaptada uma classificação do grau de dificuldade e intensidade para as trilha da UFLA, porque os manuais de implantação de trilhas encontrados são voltados principalmente para o Ecoturismo e implantação de trilhas em parque estaduais.

Como visto no mapeamento, as trilhas possuem grandes extensões, não possuindo um ponto inicial ou final bem definido. Na análise do grau de dificuldade, em termos de distância, têm-se algumas ressalvas.

Uma das classificações do grau de dificuldade mais próximas às encontradas neste trabalho é a proposta pela Prefeitura Municipal de Brotas (2003), citada por Andrade e Rocha (2008). A trilha da UFLA que apresenta um certo grau de dificuldade, devido a presença de obstáculos como troncos, é a Trilha dos Eucaliptos. Apesar de possuir distância superior a $1.500 \mathrm{~m}$, a mesma não pode ser classificada como trilha avançada, pois de acordo com Andrade e Rocha (2008), o conceito desse tipo de trilha é "distância superior a $1.500 \mathrm{~m}$, exigindo esforço físico intenso, apresentando obstáculos e exigindo o uso de técnicas específicas, como natação e escalada". Todas as trilhas da UFLA não apresentam as características citadas anteriormente, com exceção da distância, sendo necessária uma adaptação de classificação para as trilhas da universidade. Com relação ao grau de elevação, de acordo com metodologia proposta por Rocha et al. (2006), citado por Andrade e Rocha (2008), as trilhas da UFLA foram classificadas em: (a) Trilha das Lagoas: apresenta grau de elevação de 0,5\%, com relevo plano; (b) Trilha da Capela: apresenta grau de elevação de 8,8\%, com relevo ondulado; (c) Trilha da Zootecnia: apresenta grau de elevação de 11,8\%, com relevo ondulado; (d) Trilha da Estação Experimental da EPAMIG: apresenta grau de elevação de 4,1\%, com relevo plano, (e) Trilha dos Eucaliptos: apresenta grau de elevação de 0,5\%, com relevo plano.

Pode-se observar que as áreas tiveram dois tipos de classificação, relevo plano e ondulado, ou seja, grau de dificuldade leve e médio, não possuindo grau de dificuldade extremo. 
Uma última classificação e não menos importante, segundo Andrade (2003), é a classificação subjetiva. A mesma varia de pessoa para pessoa, condicionamento físico ou se a trilha é guiada ou auto-guiada. Pode-se constatar que existem vários tipos de classificação para as trilhas da UFLA, embora as mesmas tenham sido classificadas apenas com relação ao grau de elevação e distância, mesmo com poucos recursos presentes nos manuais.

\subsection{Evolução espaço temporal: mudanças na trilha}

Com o passar dos anos desde sua inauguração, a UFLA tem passado por várias mudanças em suas estruturas. Essas transformações fazem parte do processo de desenvolvimento da própria instituição, e a cada ano, com a criação de novos cursos de graduação e pós-graduação, o crescimento da população acadêmica tem aumentado substancialmente nos últimos tempos.

Modernas estruturas arquitetônicas fora edificadas e continuam sendo construídas. Talvez uma das maiores mudanças feitas na Universidade foi a duplicação da avenida de acesso ao campus novo, e a criação das avenidas norte e sul. Com essas modificações muitas trilhas tiveram uma diminuição de sua extensão e algumas desapareceram. A Figura 7A mostra como era a universidade antes da construção das avenidas norte e sul e na Figura 7B pode-se observar como essas construções modificaram as áreas no decorrer dos anos.

Figura 7. Modificações ocorridas pela construção das avenidas norte e sul. A - UFLA em 2005 (Google). B - UFLA, 2017.

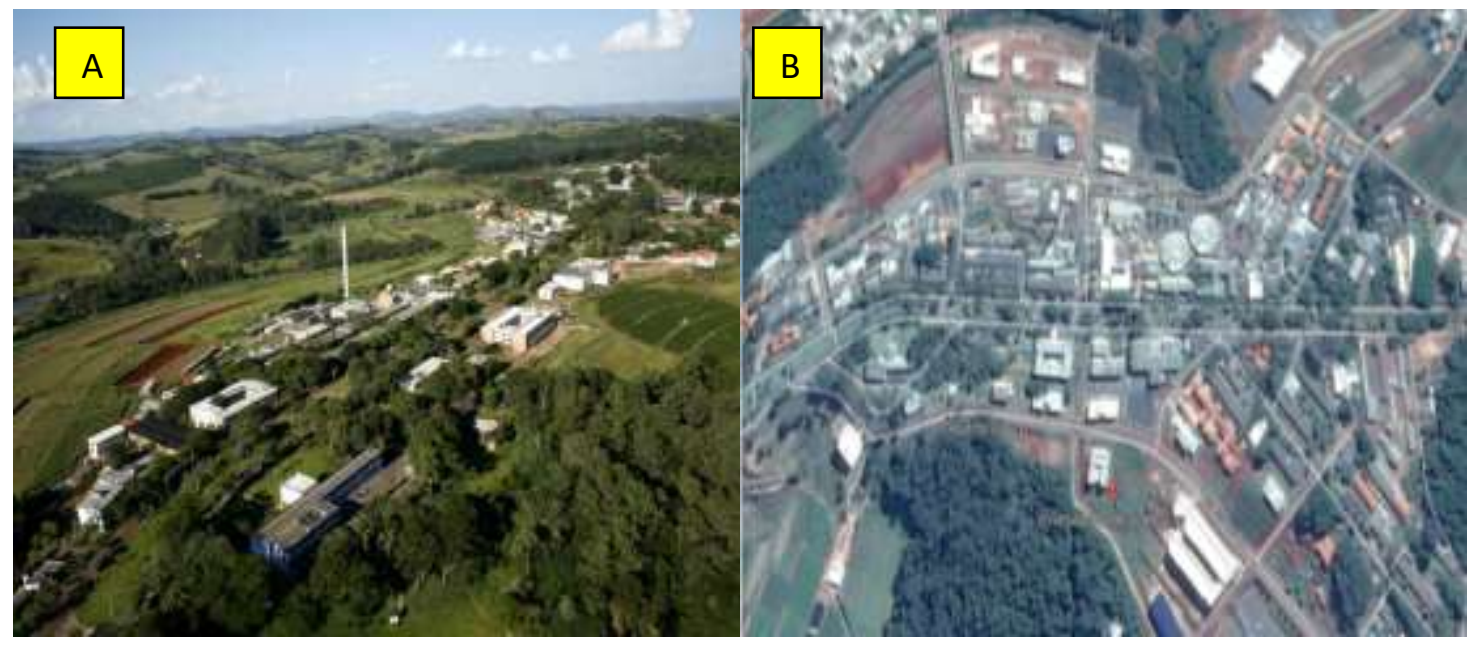

Fonte: Google Earth.

Mesmo com as pequenas mudanças que ocorreram em algumas partes da trilha, como é o caso da Trilha das Lagoas, que teve uma pequena parte modificada pela construção da nova lagoa de captação, verifica-se no mapa (Figura 8) modificação no percurso original. As setas em laranja (Figura 8A) mostram como era antes da construção da lagoa e na Figura 8B verificase como as trilhas ficaram mais retas e menos sinuosas depois da implantação da lagoa. 
Figura 8. Modificação na trilha das lagoas. A - trilha anos atrás (Google Earth). B - trilha atualmente.

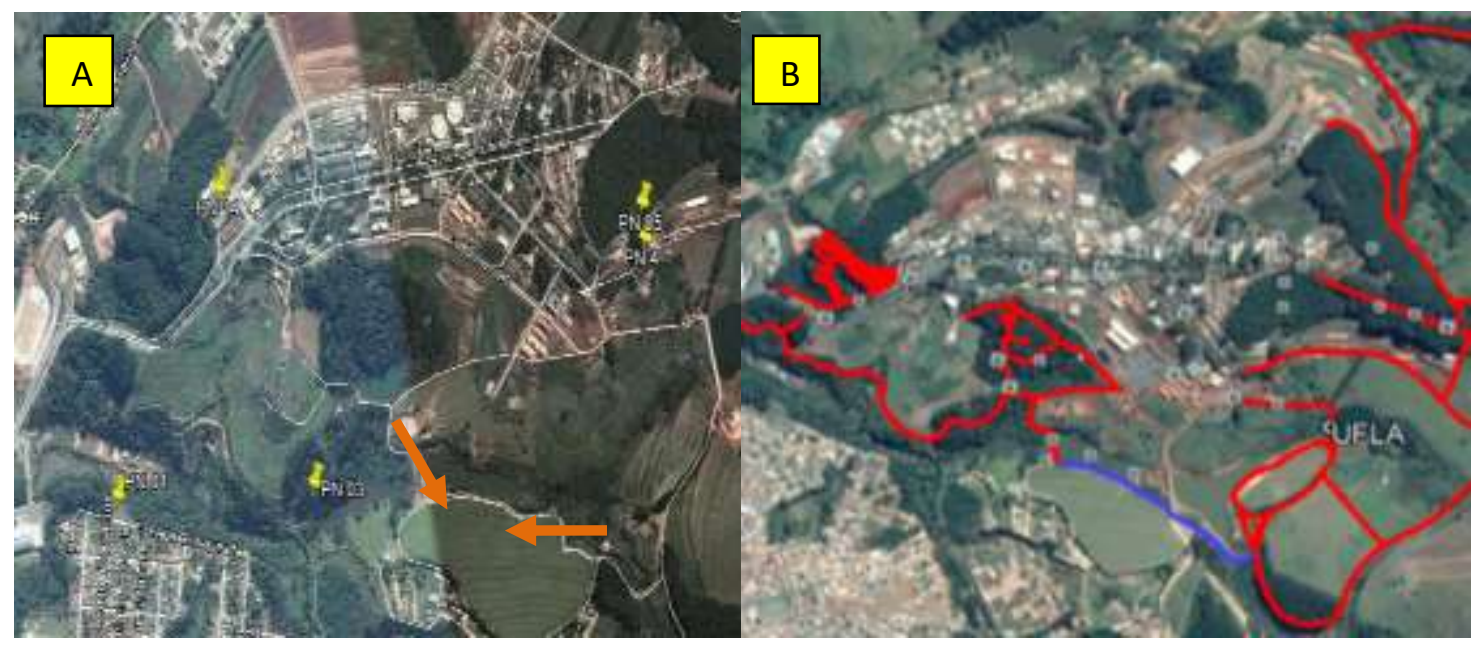

Fonte: Google Earth (2017).

\subsection{Palestras nas escolas}

As palestras tinham como temas principais a Educação Ambiental e as trilhas da UFLA, sendo apresentadas para alunos (as) do Ensino Fundamental I e II e Ensino Médio. Modificações nos conteúdos foram realizadas para adequar-se a cada faixa etária de ensino. O primeiro tema discutido foi sobre a água, recurso mais abundante do planeta. Foram abordadas a distribuição de água no mundo e no Brasil; a porcentagem de água salgada e doce existente, a poluição em rios e nascentes, assim como os principais setores da sociedade que mais utilizam água, como indústria, agricultura e uso doméstico.

Outros temas abordados foram os biomas encontrados no Brasil, o desmatamento, aquecimento global, poluição do ar e fauna encontrada no Cerrado Mineiro (Lobo-Guará, Jaguatirica, Tatu, Tucano e Capivara). Segundo Silva (2009) foram encontradas diferentes espécies de mamíferos nas áreas verdes dentro da UFLA, animais como paca (Cuniculus paca), gambá (Didelplus), tatu-galinha (Dasypus novemcinctus), mão-pelada (Procyon cancrivorus), tamanduá-mirim (Tamanduá tetraductyla), micoestrela (Calibres penicinata), furão (Galictis cuja), ouriço-caixeiro (Coendou prehensilis), veado-campeiro (Mazama gouazoupira), capivara (Hydrochoerus hydrochaeris). Recentemente, em uma reportagem publicada pela ASCOM, foi destacado o registro da aparição do lobo-guará no campus da UFLA, próximo à rodovia MG-355 (Alvim, 2016).

Além disso, verifica-se grande presença de aves no campus, principalmente na Reserva Florestal da UFLA, na Mata da Subestação, Mata da Capela e Eucaliptal, e entre as diversas espécies encontradas estão o fim-fim (Euphonia chlorotica), bem-te-vi (Pitangus sulphuratus), tangará (Chiroxiphia caudata), enferrujado (Lathrotriccus euleri), saracura-do-mato (Aramides saracura), saci (Tapera naevia) e viuvinha (Colonia colonus). Várias espécies de árvores como o pau-jacaré (Piptadenia gonoacantha), copaíba (Copaifera langsdorfii), bonifácio ou vaquinha (Maprounea guianensis), ingá bravo (Sclerolobium rugosum), canjerana (Cabralea canjerana), bico de pato (Machaerium nyctians), casca-de-barata (Xylopia brasiliensis), dentro outras (D’Ângelo Neto et al., 2008) também são encontradas na universidade.

Para finalizar a apresentação foi mostrado o mapa das trilhas (Figuras 9 e 10) em imagem trabalhada no BaseCamp e depois plotada no Google Earth. Em seguida, foram mostradas fotos das trilhas da UFLA e na sequência foi exibido o vídeo para mostrar de forma mais interativa as trilhas.

Durante a apresentação, vários temas foram abordados. Porém, a real preocupação era dar ligação entre os conteúdos, para tornar mais interessante para os alunos (as). Como visto, as áreas preservadas da UFLA apresentam uma grande biodiversidade. Um dos objetivos da palestra foi explorar o que existe dentro da instituição.

Nota-se que há uma relação entre os temas da palestra e as áreas presentes na UFLA, sendo possível trabalhar esse conteúdo de forma teórico-prática por meio de trilhas interpretativas. 
Figura 9. Mapa da UFLA apresentado nas escolas.

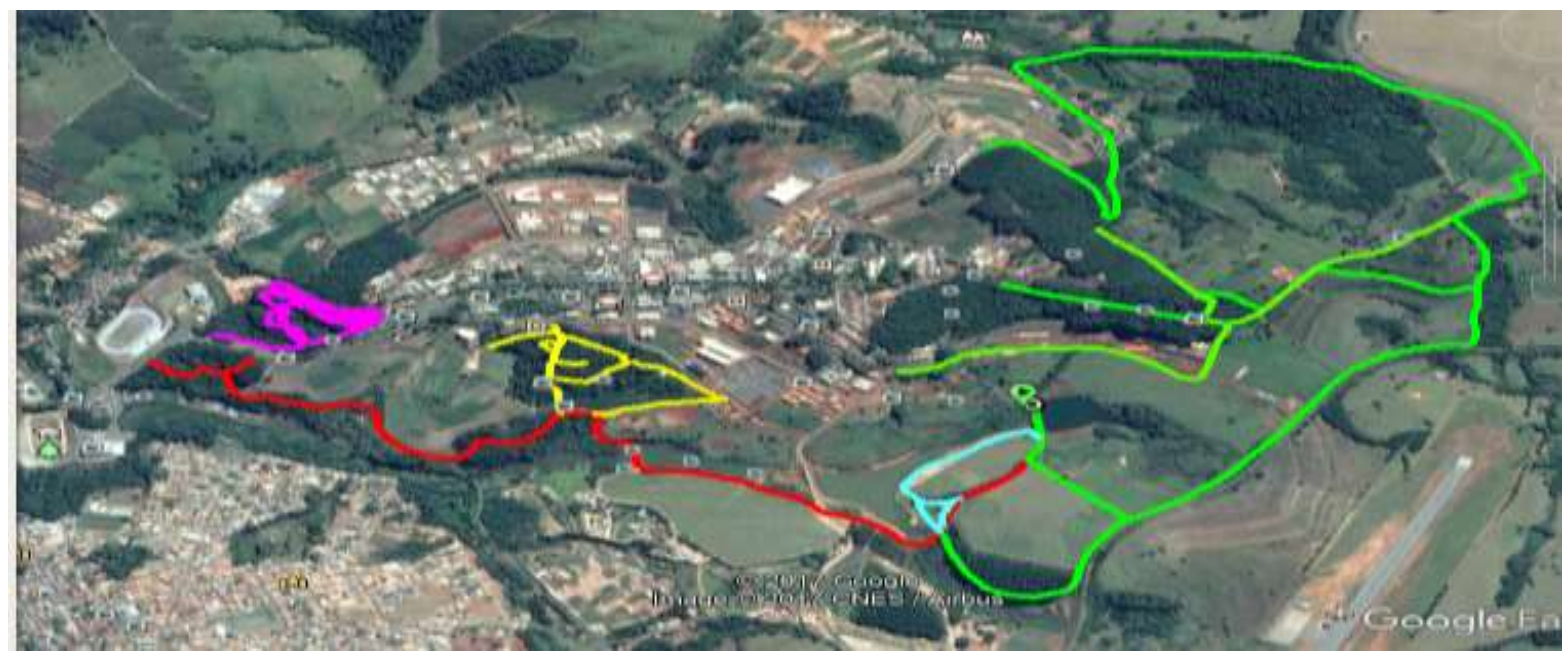

Fonte: Autores.

Figura 10. Trilha da UFLA.

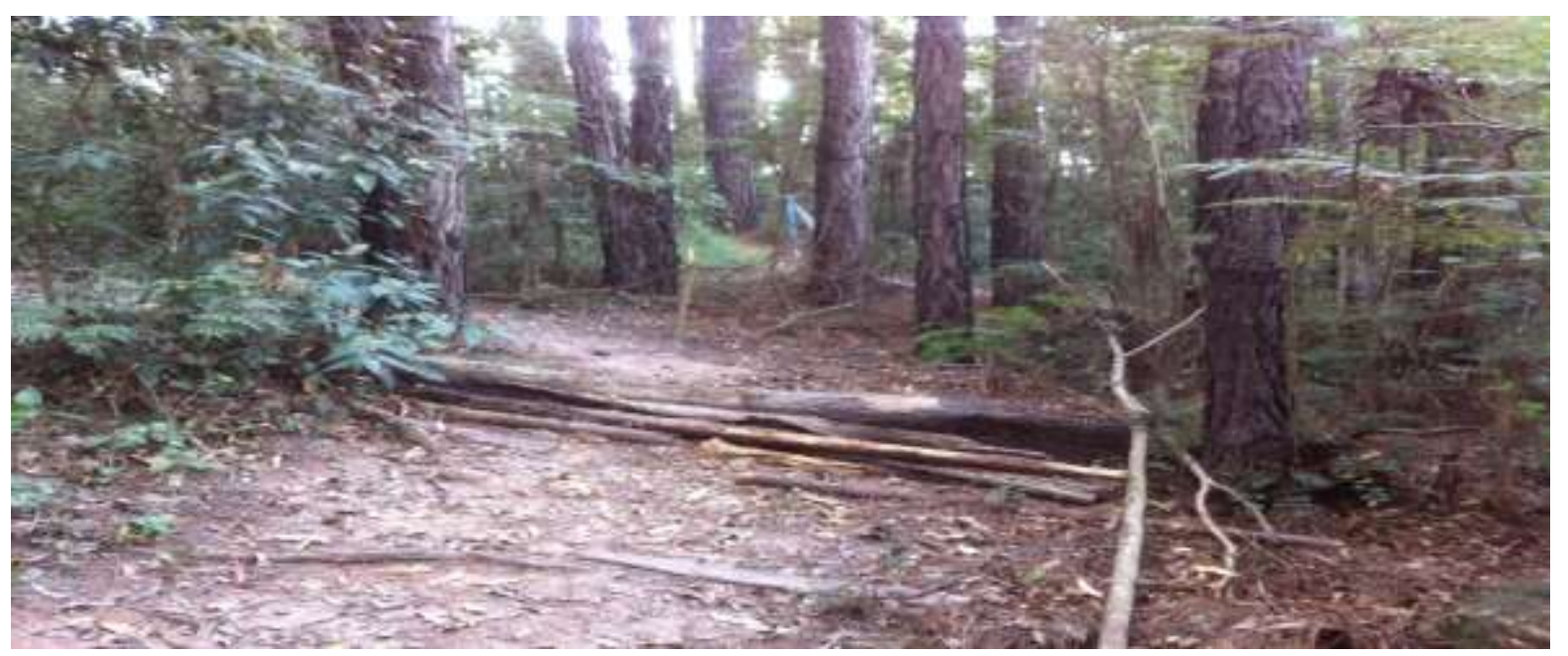

Fonte: Autores.

Mediante o exposto, torna-se importante abordar a Educação Ambiental e seus conteúdos, como meio de conscientização para práticas mais corretas com a natureza. Levar ao público a existência dessas trilhas é importante para aproximar a universidade da sociedade, já que é fundamental que as pessoas conheçam e desfrutem de forma responsável dos espaços públicos da UFLA, tão pouco conhecidos fora da comunidade acadêmica. O levantamento e classificação dessas áreas podem contribuir para futuras pesquisas em outros projetos dentro da universidade.

\section{Conclusão}

Com base no mapeamento das trilhas da Universidade Federal de Lavras, distinguem-se áreas com diferentes graus de declividade e ambientes florísticos e com fauna diversificada, o que instiga a sugestão de trilhas para alunos (as) em função da faixa etária. Para discentes do Ensino Fundamental I e II recomenda-se a Trilha das Lagoas, por apresentar baixo grau de declividade, fácil acesso, distância intermediária e pontos recreativos à beira das lagoas. Já para alunos (as) do Ensino Médio, a Trilha da Capela e Trilha dos Eucaliptos, por apresentarem um ambiente mais diversificado, seria a mais indicada, sendo inclusive propícia para a prática de atividades de aventura na natureza. 
Research, Society and Development, v. 10, n. 2, e9810212338, 2021

(CC BY 4.0) | ISSN 2525-3409 | DOI: http://dx.doi.org/10.33448/rsd-v10i2.12338

\section{Agradecimentos}

À Pró-Reitoria de Extensão e Cultura da Universidade Federal de Lavras e ao Conselho Nacional de Desenvolvimento Científico e Tecnológico (CNPq) pela concessão de bolsa e recursos para o projeto.

\section{Referências}

Alvim, A. E. (2016). Pesquisa identifica registro inédito de lobo-guará na UFLA. 2016. http://www.ufla.br/ascom/2016/06/20/pesquisa-identifica-registroinedito-de-lobo-guara-no-campus-da-ufla/.

Ambrósio, R. V., Borém, R. A. T. \& Santos, A. A. (2011). Implantação de uma trilha interpretativa nos fragmentos de mata atlântica e cerrado no centro de educação ambiental - Ecolândia - da $6^{\mathrm{a}}$ CIA IND de meio ambiente e trânsito rodoviário da polícia militar de Minas Gerais - Lavras, MG. Revista Eletrônica do Mestrado em Educação Ambiental, 27, 85-99.

Andrade, W. J de. \& Rocha, R. F de. (2008) Manejo de Trilhas: Um Manual para Gestores. IF Sér. Reg., São Paulo, 1-74.

Andrade, W. J. de. Implantação e manejo de trilhas. In: Mitraud, S (Org.). (2003). Manual de Ecoturismo de Base Comunitária: Ferramentas para um Planejamento Responsável. Brasília: WWF Brasil, 247-260.

Brasil. Secretaria de Educação Fundamental (1997). Parâmetros Curriculares Nacionais: meio ambiente, saúde. Brasília: 128p. Recuperado em 15 de janeiro, 2020, de http://www.portalmec.gov.br.

CAETANO, C. (2017). Guia do Estudante avalia UFLA como a $8^{a}$ melhor universidade pública do Brasil e $2^{a}$ de Minas Gerais. http://www.ufla.br/ascom/2017/10/17/guia-do-estudante-avalia-ufla-como-a-8a-melhor-universidade-publica-do-brasil-e-2a-de-minas-gerais/.

D’ Angelo Neto, S., Venturin, N., Oliveira Filho, A. T., \& Costa, F. A. F. (2009). Avifauna de quatro fisionomias florestais de pequeno tamanho (5-8 ha) no Campus da UFLA. Revista Brasileira de Biologia, 58(3) 463-472.

Domingues, S. C., Kunz, E., \& Araújo, L. C. G de. (2011). Educação Ambiental e Educação Física: Possibilidades para a Formação de Professores. Revista Brasileira de Ciências do Esporte, Florianópolis, 33(3) 559-571.

Google Earth. (2017). https://www.google.com.br/search?rlz=1C1GGGE_ptBRBR445BR445\&tbm=ischsa=1\&ei=G9IvWomuDYWVwASj6JA4\&q=imag em+da+ufla++pelo+google+earth.

Lima, M. (2016). Ranking destaca UFLA a como a universidade mais sustentável do Brasil e 39a do mundo. http://www.ufla.br/ascom/2016/01/25/rankingdestaca-ufla-como-a-universidade-mais-sustentavel-do-brasil-e-39a-do-mundo/.

Menghini, F. B. (2005). As trilhas interpretativas como recurso pedagógico: caminhos traçados para a Educação Ambiental. 103 p. Dissertação de Mestrado (Educação)- UNIVALI.

Oliveira, A. H., Klinke Neto, G., Gonçalves, G. R. M., Pereira, J. A. A., Vieira, A. P., \& Borges, C. P. (2010). Índice de atratividade de pontos interpretativos (IAPI) e percepção dos usuários da trilhada UFLA, MG. Revista de Estudos Ambientais. 12(2) 62-73.

Pelicioni, M. C. F. (1998). Educação ambiental, qualidade de vida e sustentabilidade. Saúde e sociedade, 7(2), 19-31.

Pereira, A. S., Shitsuka, D. M., Parreira, F. J., \& Shitsuka, R. (2018). Metodologia da pesquisa científica. Santa Maria, RS: UFSM, NTE. https://repositorio.ufsm.br/bitstream/handle/1/15824/Lic_Computacao_Metodologia-Pesquisa-Cientifica.pdf?sequence=1.

Silva, M. B. R. (2009). Perfil do usuário das trilhas do campus da Universidade Federal de Lavras - MG: uma abordagem do ecoturismo. 2009.45 p. Monografia (Especialização em Ecoturismo) - Universidade Federal de Lavras, Lavras.

Silva, M. M., Almeida Netto, T., Azevedo, L. F., Scarton, L. P., \& Hillig, C. (2012). Trilha Ecológica como Prática de Educação Ambiental. Revista Eletrônica em Gestão, Educação e Tecnologia Ambiental, 5(5), 705-719. 